\title{
O PROBLEMA DA FALACIA NATURALISTA PARA O PROJETO DE UMA ÉTICA EVOLUCIONISTA
}

Karla Chediak ${ }^{*}$ kchediak@terra.com.br

RESUMO Um dos problemas mais dificeis enfrentados pelos defensores de uma ética evolucionista é a falácia naturalista. Neste artigo, analisamos as soluções propostas por $W$. Rottschaefer e por R. Richards e verificamos não serem elas suficientes para eliminar o problema da falácia naturalista sem comprometer a especificidade da moral.

Palavras-Chave Falácia Naturalista, Ética Evolucionista, Dever, Moral

ABSTRACT One of the most difficult problems for who defends an evolutionary ethics is the naturalist fallacy. In this article, we examine the solutions proposed by W. Rottschaefer and R. Richards. We believe that these solutions are not good enough to completely eliminate the problem of the naturalist fallacy without compromising the specificity of morality.

Keywords Naturalist Fallacy, Evolutionary Ethics, Ought-Proposition, Moral

* Professora da Universidade do Estado do Rio de Janeiro. Artigo recebido em jul./05 e aprovado em jan./06.

KRITERION, Belo Horizonte, no 113, Jun/2006, p. 147-157. 
Uma das teses mais discutidas entre os filósofos da biologia é a que afirma existir uma estreita relação entre moral e evolução. Ela se baseia, fundamentalmente, na compreensão de que o homem é uma espécie natural como qualquer outra e, sendo assim, para explicar sua origem, é necessário utilizar-se apenas a sua história natural, ou seja, o processo de hominização. Só o processo evolutivo daria conta de uma explicação teórica sobre a origem e a formação das competências da espécie humana.

Em geral, a tese evolucionista sustenta que os últimos cinco milhões de anos foram fundamentais para o desenvolvimento das habilidades humanas, sejam cognitivas, sejam práticas e que a história biológica teria continuado a exercer influência a despeito de ter-se iniciado a história cultural da espécie.

Com isso, haveria muitos elos entre a espécie humana e as outras espécies animais e, embora para outros domínios como o da vida social, da inteligência e da linguagem já se aceite a influência da biologia evolutiva, com relação à moral, o problema é mais complicado. Apesar disso, alguns filósofos da biologia certos de haver uma relação bastante estreita entre moral e evolução, conceberam uma ética evolucionista. Eles sustentam que uma investigação empírica baseada na teoria da evolução pode esclarecer a natureza da moralidade, sendo capaz, inclusive, de fornecer justificação para algumas de nossas normas morais. Essa concepção de moral recebeu severas críticas, em parte porque a moral é, freqüentemente, compreendida como a expressão máxima da indeterminação e da independência do homem em relação ao resto da natureza, expressando a capacidade da espécie humana de se auto-determinar, algo jamais alcançado por outra espécie animal.

Dentre as numerosas críticas dirigidas à proposta de vincular moral e evolução uma sobressai, não apenas por ser a mais freqüente, mas por ser, possivelmente, a mais difícil de ser rebatida - a falácia naturalista. Esse termo "falácia naturalista"foi cunhado por Moore para combater a concepção naturalista e também metafísica da moral.

No entanto, reconhece-se que, antes de Moore, Hume teria apresentado pela primeira vez, em uma passagem do Tratado da natureza humana, uma dimensão do problema. Diz ele:

em todo sistema de moral que até hoje encontrei, sempre notei que o autor segue durante algum tempo o modo comum de raciocinar (...) quando de repente, surpreendo-me ao ver que, em vez de cópulas proposicionais usuais, como é e não é, não encontro uma só proposição que não esteja conectada a outra por um deve ou não deve. Essa mudança é imperceptível, porém da maior importância. (...) seria preciso que se desse uma razão para algo que parece inteiramente inconcebível, ou seja, como essa nova relação pode ser deduzida de outras inteiramente diferentes (Hume, 2001, p. 509). 
O que usualmente se compreende por essa passagem de Hume é que não é legítimo de premissas factuais derivar-se uma conclusão moral, de caráter prescritivo, na medida em que esses enunciados são de natureza distinta. Hume estaria denunciando a inconsistência de passar do "ser" para o "dever ser". Atribui-se a essa passagem de Hume um dos sentidos fundamentais da falácia naturalista.

O outro sentido da falácia naturalista foi apresentado por Moore e fica claro na seguinte passagem do Principia Ethica:

Pode ser verdade que todas as coisas que são boas são também algo mais, assim como
é verdadeiro que todas as coisas que são amarelas produzem certo tipo de vibração
na luz. Também é fato que a ética quer descobrir quais são as outras propriedades
que pertencem a todas as coisas que são boas. Porém, muitos filósofos pensam que
quando se referem a essas outras propriedades estão, de fato, definindo o bem; que
essas propriedades não são realmente "outras", mas absolutamente e inteiramente o
mesmo que a bondade. Proponho chamar essa visão de "falácia naturalista"( Moore,
1978, p. 10).

Segundo Moore, seria falacioso definir o bem em termos de propriedades naturais, pois o bem não é uma propriedade natural. Seria também falacioso defini-lo por meio de alguma outra coisa, como, por exemplo, a felicidade. Enfim, seria falacioso definir o bem, que é, por natureza, indefinível. Para ele, o bem seria uma propriedade não natural, única e indefinível.

Ao analisar o problema da falácia naturalista, Frankena, no artigo The naturalistic fallacy, distingue e correlaciona, a partir de Moore, os dois sentidos fundamentais da falácia. O primeiro apresenta a falácia naturalista como falácia lógica e o segundo, como falácia de definição, em que se definiria o "bem" a partir de uma outra propriedade como, por exemplo, uma qualidade natural.

Segundo Frankena, a falácia naturalista no sentido de falácia lógica, ou seja, a derivação de conclusão ética a partir de premissas não éticas, pode ser facilmente solucionada, com a introdução de uma premissa ética. Por exemplo, a seguinte enunciação "o prazer é bom, uma vez que é procurado por todos os homens" cometeria a falácia por estar partindo de um suposto fato "todos os homens buscam o prazer" e concluindo "por isso, o prazer é bom". Na realidade, esse seria um entimema, argumento em que uma premissa está suprimida, que poderia ser tornado válido explicitando a premissa. Nesse caso, a premissa ética seria: "O que é almejado por todos os homens é bom”. Então nada haveria de logicamente errado com o seguinte argumento: "Todos os homens procuram o prazer. O que é procurado por todos os homens é bom. Logo, o prazer é bom”. No entanto, segundo Frankena, a falácia naturalista 
não desaparece do argumento e isso porque a falácia naturalista não é, a rigor, uma falácia lógica, pois só seria caso não fosse possível explicitar a premissa oculta. O problema, então, transfere-se para o modo pelo qual se obtém a premissa ética que foi explicitada, ou seja, para o modo como se obtém a premissa: "O que é procurado por todos os homens é bom". Caso se obtenha por outra dedução, o problema é apenas adiado. Se é por definição, então, do ponto de vista de Moore, há a falácia, pois estar-se-ia identificando, ou seja, definindo uma propriedade por outra. A falácia naturalista seria, na realidade, um tipo de falácia de definição.

Frankena observa que para que certo enunciado do tipo "o que é prazeroso é bom" seja considerado falacioso, é preciso que se aceite que o bom não pode ser definido em termos de prazer, portanto, esse é o ponto de partida da argumentação e não propriamente a sua conclusão. Do contrário, corre-se o risco de cometer petição de princípio, pois "tem de saber que a característica é não natural e indefinível em termos naturais antes que se possa dizer que os defensores da definição estão cometendo uma falácia" (Frankena, 1977, p. 60). O problema é que o oponente pode não se deixar convencer que o bom é uma propriedade única e indefinível e, assim, não se cometeria nenhuma falácia.

De fato, desde que foi apresentado, o problema da falácia naturalista tem sido o calcanhar de Aquiles de todas as teses que procuram defender uma origem evolutiva para a moral, principalmente porque, independentemente de se aceitar ou não a tese de Moore, a distinção entre ser e dever ser é quase universalmente acatada. Essa aceitação deve-se em parte à evidente distinção entre enunciados que dizem como as coisas são, descritivos, e os que dizem como elas deveriam ser, prescritivos. A especificidade dos enunciados morais estaria no fato de eles serem normativos e não descritivos e o problema, apontado por muitos filósofos, é que, quando se misturam os dois, há o risco de se anular o caráter normativo dos enunciados morais. Isso ocorreria, quando fosse reduzido o dever ser ao ser, como afirma Luc Ferry, na seguinte passagem:

Ou bem reduzimos o normativo ao descritivo, o direito ao fato, a moral à história e à natureza que a determinam; porém, nesse caso, é preciso renunciar a idéia de ética normativa e se limitar a descrever comportamentos morais de maneira neutra, como se faz com o comportamento dos animais. Então, não há mais ética, apenas etologia, que, sem nenhum juízo de valor, limita-se a mostrar porque e como os animais, humanos ou não, conduzem sua vida (Ferry e Vicent, 2000, p. 86).

O risco do reducionismo e, portanto, da descaracterização da normatividade dos enunciados morais, sem dúvida, assombra o evolucionismo moral, 
mas é preciso se questionar se toda as concepções de ética evolucionista necessariamente são reducionistas como acredita Luc Ferry.

Com relação ao problema da falácia naturalista por definição, é razoável supor que o evolucionista que defende a existência de uma correlação entre moral e evolução dificilmente abraçaria a concepção de Moore de que o bem é uma propriedade simples, não natural, indefinível em termos de outra propriedade. Não faz sentido para quem considera que as habilidades humanas, sejam cognitivas, sejam práticas, tiveram origem evolutiva, conceber o conceito de "bom" como algo tão autônomo assim. Além disso, como afirma Frankena, caso não se aceite de início tal compreensão, não há falácia, pois a própria noção de propriedades não naturais, puramente intuídas, não seria aceita, e, afinal, a afirmação de sua existência não é auto-evidente e é exatamente o que está em questão e que o evolucionista provavelmente recusaria.

Desse modo, ficamos com o problema relacionado ao sentido derivacional da falácia, a saber, a passagem de enunciados factuais para enunciados normativos. Como disse Frankena, essa questão é resolvida inserindo-se uma premissa normativa. No entanto, o evolucionista deve mostrar como é obtida essa premissa sem cometer a falácia naturalista. De nada adiantaria criar um novo argumento dedutivo, porque o problema continuaria o mesmo. Resta-lhe, então, explicar como chegou a essa premissa introduzida para tornar válido o argumento que associa fatos e valores. Como observa Barrett em seu artigo Really taking Darwin and naturalistic fallacy seriously, tem-se aí um dilema, pois se essa premissa não for explicável em termos factuais, não se está relacionando o domínio da ética com o do factual e a questão se anula, pois a teoria da evolução não teria relevância nenhuma para a moral. E se ela for explicável em termos factuais, estar-se-ia cometendo a falácia derivacional.

Uma tentativa de resolver o problema da falácia naturalista de modo a defender com argumentos consistentes uma ética evolucionista é feita por William Rottschaefer, em seu artigo Evolutionary ethics: An irresistible tentation: Some reflexions on Paul Faber's The temptation of evolutionary ethics. Ao considerar a seguinte dedução falaciosa: "A evolução formou os seres humanos para que procurassem o bem da comunidade. Logo, o bem da comunidade é moralmente valoroso", procura corrigi-la, inserindo outra premissa. O argumento fica assim: "O que é moralmente valoroso é aquilo que a evolução fez os homens buscarem. A evolução formou os homens para buscarem o bem da comunidade. Logo, o bem da comunidade é moralmente valoroso". A questão é, então, a de explicar como chegamos a essa premissa inserida "O que é moralmente valoroso é aquilo que a evolução fez os homens buscarem". Para Rottschaefer, uma das formas de se evitar a falácia naturalista 
na forma derivada consiste em rediscutir a relação entre explicação e justificação. É aceito, em geral, que enunciados factuais estão sujeitos a explicação, mas os enunciados normativos não. As explicações dadas a um enunciado normativo não são relevantes para a aceitação desse enunciado, pois enunciados normativos devem ser justificados de modo a produzir sua aceitação. Por isso, ao fornecer explicação para a premissa, cometer-se-ia a falácia genética, pois uma coisa é fornecer as causas que explicam a origem de um fenômeno, outra coisa é fornecer as razões que o justificam. Os enunciados morais demandariam justificativas e não explicações. Porém, para Rottschaefer, a teoria da evolução teria um papel não apenas na explicação, mas também na justificação da moralidade e isso sem confundir ou considerar indistintos a explicação e a justificação. $\mathrm{O}$ autor aceita essa distinção e acredita que, em certos casos, como o conhecido exemplo de Kekule de que a idéia da estrutura do anel de benzeno teria vindo através de um sonho com uma cobra mordendo o rabo, pode ter sido a origem, mas não poderia justificar a fórmula estrutural do benzeno. No entanto, em outros casos, o modo como se adquire uma idéia seria suficiente para justificar a crença. Por exemplo, no caso das crenças perceptivas, a percepção é a origem da crença e é condição suficiente para justificar a crença. Esse caso seria análogo ao da relação entre evolução e moral. Se realmente é possível sustentar-se que algumas capacidades motivacionais, comportamentais e cognitivas relacionadas com a moral foram formadas ao longo da evolução da espécie humana, então, pode-se afirmar que elas sustentam, ao menos em parte, os valores humanos e pode-se também apelar a eles para justificar as ações. Transforma-se, assim, o valor adaptativo em termos de sobrevivência e reprodução em valor moral básico (Rottschaefer e Martinsen,1991, p. 398).

Um exemplo apresentado pelo autor é o de que auxiliar alguém em situação de sofrimento, dor ou tristeza é considerado um ato moralmente bom. Isso estaria associado ao raciocínio baseado na evolução de que ajudar ao outro ferido é ajudar a preservar sua vida, livrando-o de uma infecção e de uma possível morte. Além disso, preservando sua vida ajuda-se a que ele tenha filhos e possa cuidar dos seus filhos, se for o caso. A evolução teria selecionado comportamentos que favoreceram a sobrevivência e o cuidado com os filhos. Então, sobreviver e cuidar dos filhos são, geralmente, consideradas coisas boas e justificariam auxiliar alguém em situações de dificuldade.

Afirma Rottschaefer: "se podemos encontrar mecanismos que confiavelmente geram bons posicionamentos morais, então podemos apelar a eles em nossas justificações tanto quanto em nossas explicações" (1997, p. 376). Identificar os mecanismos que geraram certos posicionamentos de ordem moral é, 
para o autor, uma questão empírica, portanto, refutável e de natureza provável, baseados em mecanismos a posteriori e não a priori. Além disso, Rottschaefer diz não defender que a teoria da evolução seja suficiente para justificar a prática moral, mas insiste ser ela um dos seus elementos. A rigor, nenhuma teoria sozinha, seria suficiente para justificar as crenças morais.

O cerne do argumento de Rottschaefer é conceber que a tese da evolução pode ser tanto fonte de explicação, quanto de justificação, de modo que o que foi favorecido em termos adaptativos, de sobrevivência e reprodução, pode justificar sua transformação em valor moral. O problema, a nosso ver, é que isso não pode ser generalizado sem produzir alguns absurdos. Não é só possível, mas bastante plausível que motivações e comportamentos tenham evoluído, portanto, favorecido a sobrevivência e a reprodução dos indivíduos de um grupo, mas que nem por isso seriam considerados morais. E se isso for verdadeiro, não pode ser com base na evolução que distinguimos o que dela é incorporado num sistema moral e o que fica fora dele. A evolução torna-se insuficiente para fornecer uma justificativa para a moral e aquilo que evoluiu e que também é considerado moralmente bom tem de estar sujeito a um outro tipo de critério, não mais de caráter evolutivo.

Outro filósofo da biologia que procura rebater o argumento da falácia naturalista é R. Richards em $A$ defense of evolutionary ethics. Para ele, a teoria evolutiva não deveria repetir os erros do passado, afirmando que se algo evoluiu, então, é bom ou ainda supor que se podem estabelecer hierarquias em função do que é mais evoluído e menos evoluído. Cada cultura específica responderia por seu arranjo social particular. No entanto, Richards defende que há uma relação direta entre evolução e normas morais. A falácia naturalista não descreveria realmente uma falácia, sendo possível derivar normas de fatos sem cometer nenhuma falácia. Com isso, poder-se-ia justificar por meio do recurso evolutivo a premissa ética de um argumento misto (Richards, 1995, p. 269).

Richards argumenta que qualquer sistema ético lida com pelo menos três considerações que podem e devem ser tratados de modo empírico. Primeiro, uma compreensão da natureza humana, do que é o homem, de suas competências e das relações entre os indivíduos. Segundo, uma compreensão de como as considerações sobre o que é moralmente bom se realizam na sociedade humana. E, terceiro, o modo como devem ser construídas as justificações dos sistemas e dos princípios morais (ibidem, p. 271). É com relação ao terceiro aspecto que incide a questão importante, porque Richards reconhece que é necessário encontrar-se uma forma de justificar uma norma que tenha origem evolutiva como, por exemplo, a que diz que o bem da comunidade é o maior 
bem moral. Isso seria possível, compreendendo-se que justificar é demonstrar que uma proposição ou um conjunto de proposições conforma-se com um conjunto de proposições factuais aceitáveis e de práticas aceitáveis. $\mathrm{O}$ argumento baseia-se no fato de que um sistema não pode justificar seus próprios princípios, ainda que os princípios devam ser justificados. Assim, mesmo que as proposições possam conformar-se com princípios mais gerais, a cadeia tem de terminar em algum ponto. Se não se aceita serem eles postulados, evidentes por si mesmos ou baseados em autoridade, então, não há como evitar o apelo ao empírico. E é isso que ele pretende fazer com relação ao princípio ético supracitado que diz: “o bem-estar da comunidade é o maior bem moral”. É a evolução que teria equipado a espécie humana para que os indivíduos protejam sua vida, a de seus filhos e de sua comunidade e isso aparece nas normas e nos valores morais.

O cerne do argumento de Richards está na analogia estabelecida entre os raciocínios do tipo: "se há relâmpago, então, deve trovejar" e o que diz: "se sou membro da universidade, devo preparar aulas adequadamente" ou ainda: "se a espécie humana evoluiu de modo a promover o bem da comunidade, então, cada um deve agir pelo bem da comunidade". O argumento que justificaria a tese seria

a evidência mostra que a evolução realmente construiu os seres humanos para agirem pelo bem da comunidade; agir pelo bem da comunidade é o que significa ser moral. Uma vez que seres humanos são seres morais, condição inevitável produzida pela evolução, cada um deve agir pelo bem da comunidade (Richards, 1995, p. 281).

Richards relaciona o uso que se faz do termo "dever" nas ciências naturais, cujo significado indica o que é provável, o que é esperado com o sentido moral de dever. De certo modo, ele acredita que os dois sentidos não estão tão distantes como se costuma julgar. Richards afirma retirar seu modelo de Alan Gewirth, cujo argumento, segundo Richards é o de que o conceito de "dever" significa fundamentalmente o que é demandado por razões que se originam de um contexto estruturado. O que se espera ocorrer em condições normais, caso não haja nenhuma interferência externa. Isso valeria tanto para proposições de ciência, quanto para as outras proposições, como as morais. Por isso, diz ele: "reconhecemos que um dado princípio moral, em geral aceito, ratifica a derivação das reivindicações de direito das afirmações empíricas sobre as necessidades de todos os homens" (ibidem, p. 278). Então, não haveria falácia em se justificar a suposta premissa ética: "Os homens devem agir tendo em vista o bem da comunidade" por meio da seguinte afirmação: "A evolução dispôs a espécie humana de tal modo para que aja pelo bem da comunidade". 
A justificativa por meio de recurso aos fatos sustenta-se por essa assimilação do sentido moral de dever para o sentido de dever utilizado pelas ciências. No entanto, não é muito evidente que essa identificação possa ser feita, sem forte prejuízo para o sentido de dever moral. Concordamos com as críticas de K. Ferguson em Semantic and structural problems in evolutionary ethics em que diz que, ao fazer essa assimilação, o que se perde é o caráter prescritivo ou avaliativo associado aos enunciados morais. Para ele, haveria dois sentidos distintos de "dever", um indicando o que é provável e que seria o uso científico e o outro indicando o que é requerido e que daria conta do sentido moral (Richards, 1995, p. 281). Desse modo, aceitar que o sentido do termo "dever", significando o que é esperado, possa ser equivalente ao sentido moral do termo, que significa o que é demandado, mesmo que eles tenham semelhanças, na medida em que cada um supõe um contexto estruturado dentro do qual se forma, não parece muito convincente.

É notável que as duas propostas analisadas e que procuram responder ao problema da falácia naturalista estejam sujeitas a críticas consistentes. $\mathrm{O}$ estabelecimento de uma relação entre evolução e moral não pode ser feita à custa do comprometimento da especificidade da moral, ou seja, por meio da indistinção entre o que é justificar e explicar ou por meio da indistinção entre dever moral e dever não moral. Nesse sentido, parece-nos que o projeto de uma ética evolucionista dificilmente se livra do problema da falácia naturalista na sua forma da falácia derivacional ou ainda da falácia genética ou de definição. No entanto, isso não significa negar a relação entre moral e evolução, mas reconhecer seus limites.

De fato, defender uma ética evolucionista de caráter objetivo mostrou-se bastante problemático por não escapar da falácia naturalista. Por isso, como afirma Michael Ruse, a concepção subjetiva da moral parece ser a mais compatível com a tese evolucionista da moral (Ruse, 1995, p. 321). Para esse autor conceber a ética como subjetiva evitaria a falácia naturalista na forma da definição, porque não sendo objetivos, os valores morais não poderiam ser assimilados aos factuais. Também evitaria a falácia naturalista na forma derivada, porque se o evolucionismo só fornece explicação, não poderia pretender nem fundamentar nem justificar os valores e normas morais.

Assim, uma perspectiva subjetivista da moral, por não reconhecer a existência nem de fundamentação nem de justificação para os valores morais, só poderia basear-se nas inclinações emocionais da espécie. No entanto, uma ética evolucionista subjetiva não basta para dar conta da experiência humana, porque o evolucionista não pode eliminar essa dimensão da ética. Não é possível 
negar que a moral requer justificação que serve para fornecer razões a favor de determinadas normas, estabelecendo a razão da crença.

É verdade que para os evolucionistas que defendem uma relação entre moral e evolução não haveria um fundamento $a$ priori para a moral. Isso não quer dizer que a moral deva ser concebida como irracional, no sentido de ser apenas manifestação direta das disposições emocionais da espécie, tais como os sentimentos de obrigação, culpa e compaixão. Essas seriam importantes na medida em que geram o comportamento de aprovação e reprovação de certos comportamentos, mas seriam insuficientes para dar conta do comportamento moral humano que requer justificação.

Se a proposta de compreender a moral por meio da evolução esvazia o projeto de encontrar fundamentação que forneça razões necessárias para que nossas normas sejam como são, ela pode, com base na história contingente da espécie, fornecer informações e explicações de por que são do jeito que são. Assim, as reflexões com base na evolução têm importantes contribuições a dar, pois podem explicar as motivações que foram e ainda são partes das normas vigentes nas sociedades humanas, porém, mesmo que improvável, é sempre possível que elas deixem de ser. $\mathrm{O}$ fato de terem sido geradas pela evolução explica sua provável permanência, mas esse fato por isso só não parece suficiente para justificar sua permanência.

\section{Referências Bibliográficas}

BARRETT, J. Really taking Darwin and naturalistic fallacy seriously. Biology and Philosophy, 6, p. 433-437, 1991.

COSMIDES, L.; TOOBY, J.; Lieberman, D. Does morality have a biological basis? An empirical test of the factors governing moral sentiments relating to incest. Proc. Royal Society Lond., 2003.

FERGUSON, K. G. Semantic and structural problems in evolutionary ethics. Biology and Philosophy, 16, p. 69-84, 2001.

FERRY, L.; VICENT, J-D. Qu'est-ce que l'homme? Sur les fondamentaux de la biologie et de la philosophie. Paris: Odile Jacob, 2000.

FRANKENA, W. K. The naturalistic fallacy. In: FOOT, P. Theories of Ethics. Oxford: Oxford University Press, 1977.

HUME, D. Tratado da natureza humana. Tradução Déborah Danowski. São Paulo: UNESP, 2001.

MCINTYRE, A. After virtue. Indiana: University Notre Dame Press, 1984.

MOORE, G. E. Principia ethica. Cambridge: Cambridge University Press, 1978. RICHARDS, R. J. A defense of evolutionary ethics. In: THOMPSON, P. (Ed.). Issues in evolutionary ethics. New York: State University New York, 1995. 
ROTTSCHAEFER, W. Evolutionary Ethics: An irresistible temptation: Some reflections on Paul Farber's The temptation of evolutionary ethics. Biology and Philosophy, 12, p. 369-384, 1997.

ROTTSCHAEFER, W.; MARTINSEN, D. The insufficience of supervenient explanations of moral actions: Really taking Darwin and the naturalistic fallacy seriously. Biology and Philosophy, 6, p. 439-445, 1991.

RUSE, M. Evolutionary ethics: a phoenix arisen. In: THOMPSON, P. (Ed.). Issues in evolutionary ethics. New York: State University New York, 1995. 